\title{
Communication Literacy in Undergraduate Studies of Tertiary Education in Greece
}

\author{
Evangelia Raptou
}

\section{ABSTRACT}

Communication Literacy of teachers set the conditions for successful teaching and pedagogical work in the 21 st century school. The post-doc research aimed to: investigate if and to what extent communication is offered as a self-standing subject in tertiary education at undergraduate level, aiming at improving students' communication skills' determine the thematic units in which communication proves to acquire particular importance ${ }^{\cdot}$ investigate the communication types and forms on which focus is placed make comparable formulations between theoretical recognition of communication and its practical implementation in education. The ultimate goal is to form the basis of proposals for the comprehensive inclusion of basic communication courses in Greek universities, in case it is ascertained there are shortages in teaching communication pedagogy and instructional communication at undergraduate level or fragmented references. The results have shown that a comprehensive programme of systematic teaching of instructional communication and communication pedagogy at undergraduate level is missing.

Keywords: Communication Literacy, Communication Pedagogy, Tertiary Education.

\section{INTRODUCTION}

Education in the 21 st century aims at developing skills of major importance, among which communication holds a leading position (Binkley et al., 2012) [4]. Communication literacy of teachers set the conditions for successful teaching and pedagogies for 21 st century schools [11], [2], [22], [9].

Communication Education differs from communication in other contexts and presents three epistemological fields [20], [22]: a) Communication Pedagogy, which aims at teaching the subject of communication and examining the communication issues that play an important role in the development or degradation of students' communication competence: efficient communication methods, management of students' communication stress, communication programmes to cultivate and improve speech. b) Developmental Communication, which concerns the progression of development of communication skills, the progression of acquisition over time, which is a condition for teachers' successful teaching. c) Instructional Communication, which looks at: ways of utilizing communication principles and methods during the teaching process, teachers' communication skills and the role of communication in the learning process.

Communication Pedagogy occurs at three levels: (1)
Published Online: December 13, 2020

ISSN: $2736-4534$

DOI : 10.24018/ejedu.2020.1.1.9

Evangelia Raptou*

University of the Aegean, Rhodes, Greece.

(e-mail: raptou@rhodes.aegean.gr)

*Corresponding Author personal and interpersonal, where any educational communication within the framework of a school class offers an interpersonal communication circumstance (2) teaching and (3) social [20]. The strategies developed, laying the foundations for the creation of responsible and creative citizens, aim at developing their sociability and their smooth socialization.

Interpersonal communication, verbal and non-verbal, as well as media or digital communication, is recognized and set as a basic skill in the programme P21 Framework for 21st Century Learning, which is implemented by thousands of teachers and hundreds of schools in the USA as well as in other parts of the world, aiming at creating people able to think critically and communicate efficiently, solve problems, and cooperate. The success of the programme is defined as acquisition of skills and knowledge that will bridge the gap between the skills acquired by students during their training and the skills required by society and labour market in the 21 st century [10].

The recognition of the importance of a teacher's communication skills in transmitting the educational message, managing the class, and interacting with students in class obliges the teacher to adopt such communication skills [3]. As the development of students and their academic background depend entirely on the professional attitude of teachers, it is every teacher's duty to teach his/her 
students and prepare them on how to deal with all kinds of situations and achieve their professional goals. The teacher's most important skill is to work for the creation of a good relationship between teacher and students [18].

The importance of communication skills, so Communication Literacy, is evidenced by research findings. The study conducted by David Andrade [1] showed that communication is an essential and dominant factor affecting students' academic achievements, leading to the conclusion that it is necessary for a teacher to adopt communication skills. Khan et al. [11] found that teaching in general is considered as $50 \%$ knowledge and $50 \%$ interpersonal or communication skills, meaning that for a teacher it is not so necessary to have knowledge as it is to have communication skills. Same conclusions were reached by a study conducted in 2018 in a primary school in Sukoharjo, Central Java province in Indonesia [2]. Students interact easily with the teacher when the teacher has efficient communication skills. The importance of efficient communication in tertiary education was shown by the research conducted by Duta, Panisoara \& Panisoara [8]. The research involved a total of 245 individuals from four universities in Romania and its findings confirmed that without communication the teaching and learning processes do not take place. Teachers with communication skills create a successful teaching and learning environment for students. The researchers reached the conclusion that the need of restructured programmes to include communication training for the teaching staff of tertiary education becomes obvious. Other studies have also shown that those selected to teach communication must previously have been taught communication by communication experts and specialists. Communication scientists also stress the need of training students in efficient and appropriate communication through specific curricula in tertiary education [16].

Therefore, the implementation of Communication Pedagogy, its utilization in school life, educational practice and teaching process, requires teachers of all education levels to receive appropriate training from specialized trainers in appropriate education institutes. In higher education institutions, every emerging professional - teacher and pedagogue in this case - learns how to communicate, optimizes communication, receives training on "cultivated" communication. Teachers and pedagogues must be professionals, applying the communication principles that make their multifaceted work efficient.

Regarding the Greek education reality, there is the phenomenon of cognitive antinomy. On the one hand, there is increased interest - diffused in books, papers, conference proceedings, but also in online scientific platforms - and on the other hand, in practice there is indifference about an institutionalised, methodical and organized scientific and governmental effort to integrate Communication Pedagogy as a distinct subject.

\section{Purpose OF The Study}

In this "century of communication", as the 21 st century has been called, the previous section showed the importance of this post-doc research regarding its originality, its contribution to scientific knowledge and its relevance with the research orientation and subjects of the Department of Sciences of Preschool Education and Educational Design, University of the Aegean. The research interest is particularly high also from the pedagogical point of view, given that teaching communication courses in tertiary education contributes to the respective training of those people who perform particularly important pedagogical work, the training of teachers-pedagogues, as communication lies at the heart of every social relationship, particularly of the relationships developed in school environment. Moreover, school environment is linked with communication circumstances and goals entirely dependent upon the personality of the individual, the teacher in this case, whose communication choices affect his/her relationship with students and therefore the quality of the educational and pedagogical work [21], [13].

Based on scientific data of Pedagogical Science, it is commonly accepted that fundamental goals of school and education include shaping students' personality and integrating students in the social system. The converging view of Pedagogical Science experts as Konstantinou [12] stresses is that "a personality is considered accomplishedfulfilled when completion of communication and act has been acquired, that is when a person is able to deal with and solve, in a rational and, therefore, efficient way, personal and social issues, without disappointing own and others' expectations" and that "students need knowledge and skillscompetences to learn how to think and judge, interpret the physical and social world around them but also manage it in an efficient way and be able to communicate with it". Therefore, the organization of the communication relationship and the increased communication expectations, which constitute basic parameters of an efficient school, are the duty and responsibility of teachers, who commit to implementing the above-mentioned pedagogical goals, and their training in communication matters proves an inevitable need.

The review of relevant literature showed a significant gap in research about teaching "communication" subjects at undergraduate level in university schools that prepare teachers for primary and secondary education, pedagogues who offer valuable educational and pedagogical work. Relevant bibliographic references were limited to investigating the communication relationship between teachers-trainers and students-learners but did not touch upon its teaching dimension [19]. Extending the research to the level of Greek national $\mathrm{PhD}$ theses, a similar gap was ascertained, as all theses that built around the axis of "communication" were not investigating the teaching dimension of "communication" subjects in tertiary education at undergraduate level. More specifically, the search in the National Archive of $\mathrm{PhD}$ Theses in the scientific field of "Education" with the term "communication" as key word returned 2,002 $\mathrm{PhD}$ theses, of which only 16 contained the notion of "communication" with a pedagogical dimension. The search in the scientific field of "Other Humanities" with the same criterion returned $353 \mathrm{PhD}$ theses, of which only 1 concerned the pedagogical dimension of the term "communication". All the above demonstrate the originality of this post-doc research. 
The post-doc proposal was targeted to the research and study of the characteristics of teaching communication pedagogy and instructional communication, as these are reflected in undergraduate curricula. More specifically, the aim of the post-doc research was to: a) investigate if and to what extent communication is offered as a self-standing subject in tertiary education at undergraduate level, aiming at improving the students' communication skills (b) determine the thematic units in which communication proves to acquire particular importance (c) investigate the communication types and forms on which focus is placed, in order to support the importance of the subject of communication pedagogy and instructional communication (d) correlate and make comparable formulations between the rhetoric formed at theoretical level about the value of communication and the vision of the university condition at practical level.

\section{METHODS}

60 Study Guides from 60 departments of 13 university schools, which correspond to 12 Universities in the Greek territory, constituted the object of research. Departments were divided into 9 categories: 9 of Preschool Education, 10 of Primary Education, 6 of Philology, 5 of Philosophy, 9 of History and Archaeology, 7 of Social and Mediterranean Studies, 4 of Psychology, 5 of Theology and 5 of the Science of Physical Education \& Sports.

Of the 60 Study Guides, 48 were of academic year 20192020, 6 of 2018-2019, 5 of 2017-2018 and 1 concise study guide of 2016-2017, which referred to a Study Guide of 2011 for the detailed description of the courses.

The methodology includes search and study of the study guide of each University Department of Humanities. Through the detailed description of the subjects of the current study guide (content analysis and interpretation), the following was examined (a) reference to subjects that are relevant with the development and improvement of the communication skills of the Department graduates and (b) if this reference is determined from the beginning, that is if there is a self-standing communication subject or if communication is a sub-subject within the framework of teaching other subjects.

\section{RESUlTS}

The research of Study Guides concerns a high number of subjects. Considering that the average number of subjects required to obtain a university degree is 45 for each department, the total number of subjects examined were approximately 2,700. The examined fields were three: titles, goals and learning outcomes, contents. Of the total 2,700 subjects, 706 contained the term "communication" at the three examined levels. The results per examined level are presented below.

\section{A. Titles of Subjects}

The research showed that the term "communication" is mentioned in 75 subject titles, of which 33 belong to departments of Preschool Education, 21 to departments of
Primary Education and the remaining 21 titles are shared among the remaining 7 categories of departments.

There were only 8 subjects containing the term "communication" in their title with pedagogical significance, while 43 of them concerned ICTs (Information and Communication Technologies). If we consider that the subjects in which the term "communication" was correlated to the fields of people with disabilities (4 in total) and interculturality ( 2 in total) have or are likely to have pedagogical significance, the final number of subjects referring to "communication pedagogy" amounts to a total of 14. In Chart 1, the 14 subjects correspond to $0 \%$ of subjects. The same applies to Charter 2, where the 8 subjects correspond also to $0 \%$ of subjects. Therefore, the fractional form of correlation between the number of subjects containing "communication pedagogy" in their title and the total number of subjects required to obtain a university degree in the 60 departments is expressed as 8 to 2,700 or 14 to 2,700 subjects (Chart 1, Chart 2).
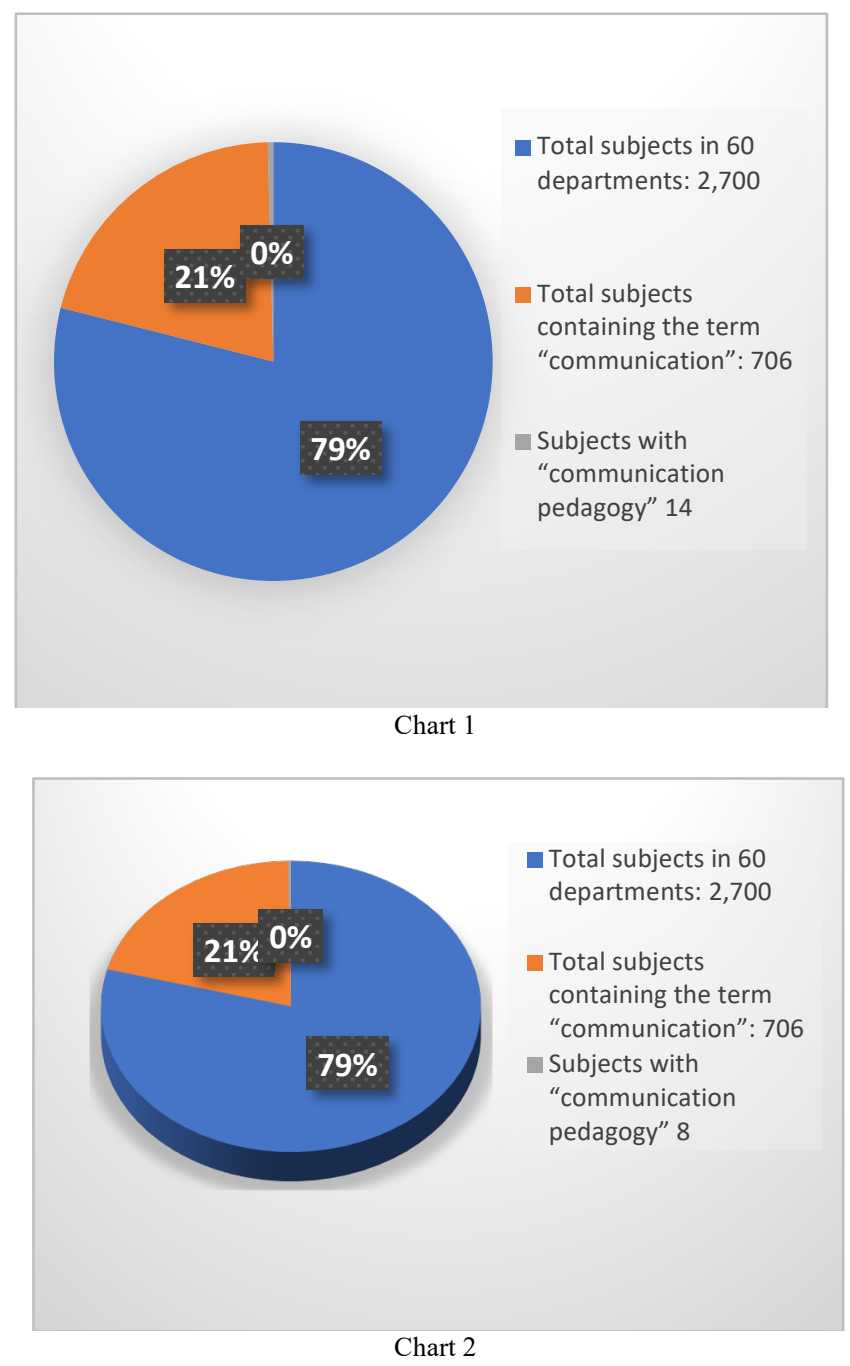

The 8 subjects correspond to three different categories of departments: Preschool Education, Primary Education and Philosophy and as for the subject type, only one is a required subject.

Of these 8 subjects, there is parallel reference to "communication pedagogy" goals, learning outcomes and content in 6 subjects. 


\section{B. Goals and Learning Outcomes}

The research showed that the term "communication" with pedagogical significance refers to the goals and learning outcomes in 402 subjects, of which 115 in departments of Preschool Education, 116 in departments of Primary Education, 68 in departments of Physical Education \& Sports, followed by the departments of Social \& Mediterranean Studies with 27 subjects, HistoryArchaeology with 25, Theology with 19, Psychology with 15, Philology with 13 and Philosophy with 4 . Of the total of 402 subjects, "communication pedagogy" is mentioned only in 49 subjects, which correspond to 7 different categories of departments: mainly Preschool Education, Primary Education, and 17 in the remaining departments, while in the departments of Philosophy and Theology there is no relevant reference. (Apart from the field of Pedagogy, the notion of "communication" is correlated to another 54 sectors, several of which could constitute a more general field).

Regarding the subject type, these 49 subjects are distributed as follows: 12 are required, 17 required elective, 19 elective and 1 Seminar. The fractional form of correlation of these subjects with the total number of the subjects required to obtain a university degree is expressed as 38 to 2,700 subjects.

\section{Content}

The research showed that the term "communication" with pedagogical significance is mentioned in the contents of 425 subjects, of which 129 concern departments of Primary Education, 103 departments of Preschool Education, followed, by a great difference, by the other departments: Psychology with 43 subjects, History-Archaeology with 37, Philology and Physical Education \& Sports with 28 subjects, Social \& Mediterranean Studies with 26, Theology with 17 and Philosophy with 14.

Of the total of 425 subjects, those having contents mentioning the term "communication" with pedagogical significance are 70 . Of these, the contents of 48 provide further information offering either a short or a more detailed context, while in the contents of 20 subjects the notion of "communication" has a general and vague meaning. Two of the 70 subjects concern people with disabilities.

Once again, the departments winning the first place in referring to the term "communication" with pedagogical significance are the departments of Preschool Education with 22 subjects and the departments of Primary Education with 26, followed by the remaining ones: 12 for the departments of Psychology, 3 for the departments of History-Archaeology, 2 for the departments of Philology, Philosophy and Physical Education and 1 for the department of Theology.

In addition, regarding the contents, the following have been observed:

- In many subjects, the text of contents is the same as goals and learning outcomes

- In some of them, the text of contents is exactly the same

- Two of them are of experiential type

Of the total of 70 subjects, 28 belong to the type of elective subjects, 25 are required, 14 are required elective, 2 are seminars and 1 is tutorial.

However, the section of contents was studied to ascertain how many other subjects - in addition to those containing the term "communication" with a pedagogical significance describe aspects of the communication phenomenon. The research showed 125 subjects, which include also the abovementioned 48 subjects that concern "communication pedagogy". It was found out that aspects of the communication phenomenon appear also in the remaining 77 subjects that do not concern "communication pedagogy".

The individual sections that concern the "teaching" of communication amount to 33; the most frequent one was the reference to verbal and non-verbal communication with 23 subjects, school - family - community communication with 11 subjects, analysis of the notion "communication" with 10 subjects, communication Theories with 8 subjects, mediated, intercultural and interpersonal communication in the classroom with 7 subjects, conflict management and communication problems-disorders with 6 subjects, communication strategies and techniques with 5, linguistic communication, public relations, interpersonal communication-interpersonal relations and communication models with 4 subjects, followed by the remaining themes with very few references.

In these subjects, the "communication" phenomenon is rarely examined from multiple points of view within the same subject. This advantage can be found in the following 11 subjects: 1) Pedagogical Relations and Interactions 2) Communication Pedagogy in Preschool and Primary education 3) School, family and community communication 4) Educational management and operation of school units 5) Speech and language education 6) Organizational Behaviour 7) School Pedagogy I 8) Application of social psychology in education 9) Intercultural education 10) Sociology of Communication 11) Communication and public relations. Of these, the first 8 subjects contain the term "communication" with pedagogical significance.

\section{Conclusions in Relation to Research Goals}

Regarding the $\mathbf{1}^{\text {st }}$ goal: "investigate if and to what extent communication is offered as a self-standing subject in tertiary education at undergraduate level, aiming at improving students' communication skills", the research showed that the communication phenomenon is not taught at university. As mentioned earlier, only 8 or, in the best-case scenario, 14 subjects contain in their title the notion of "communication" with pedagogical significance. The expected result would be to teach 60 required subjects, one in each department, following a comprehensive and organised schedule, with full reference to each communication component, followed by courses of handson experience. The total of 8 or 14 subjects does not provide a satisfactory proportion.

The teaching of ICT subjects, which increasingly attract the departments' interest, as the ones that contain "ICT" in their title are 43 , cannot be considered to bridge the gap as a form of mediated communication.

Regarding the $\mathbf{2}^{\text {nd }}$ goal: "determine the thematic units in which communication proves to acquire particular importance", the research showed that the thematic units are not always the same around the three axes: titles, goals- 
learning outcomes and content. Therefore, it can be stated that:

- In titles: the term "communication" acquires particular importance in the thematic unit related to ICTs (Information and Communication Technologies) (43 subjects)

- In goals and learning outcomes: communication acquires particular importance in the thematic unit related to pedagogy: 19 subjects, Art (theatre, dance, cinema, literature): 17 subjects, ICTs (Information and Communication Technologies): 16 subjects, foreign languages: 8 subjects, mass media: 6 subjects, Management and Administration: 4 subjects.

- In contents: the term "communication" acquires particular importance in the thematic unit related to: Pedagogy: 70 subjects, ICTs (Information and Communication Technologies): 45 subjects, Art (theatre, dance, cinema, literature): 25 subjects, Psychology: 24 subjects, Language teaching: 19 subjects, Linguistics: 19 subjects, LaboratoriesHands-on experience: 17 subjects, foreign languages: 15 subjects, mass media: 13 subjects, people with disabilities: 12 subjects, Museums: 11 subjects, Sociology (of Culture, knowledge, communication, work, health, contemporary imaginary, media): 11 subjects and Management and Administration: 7 subjects. The remaining thematic units follow with very few references.

Regarding the $3^{\text {rd }}$ goal: "investigate the communication types and forms on which focus is placed, in order to support the importance of the subject of communication pedagogy and instructional communication", the research showed that special focus is placed on verbal and non-verbal communication (23 common references by equal subjects), with the non-verbal communication taking the lead. It is followed by school - family - community communication in 11 subjects, definition and analysis of the notion of "communication" in 10 subjects, communication theories in 8, mediated communication in 7, intercultural communication in 7 , interpersonal communication in the classroom in 7 , sports and communication in 6 , conflict management in 6 , communication problems and disorders in 6 , communication strategies and techniques in 5 and then linguistic communication, public relations, interpersonal communication-interpersonal relations and communication models, ethnography of communication, communication in health, ethics of communication, learning theories with the use of ICTs, Management and Administration of educational units and Organizational communication with 4 subjects, as well as the ways of dealing with communication problems with references to 3 subjects.

As a reminder, it is clarified that, except for the 125 subjects that make an explicit reference in the contents to some communication form or aspect, in the remaining subjects up to number 425 reference to the term "communication" is general and vague.

Regarding the $4^{\text {th }}$ goal: "correlate and make comparable formulations between the rhetoric formed at theoretical level about the value of communication and the vision of the university condition at practical level", some estimates can be tentatively formulated. An explanation about the lack ascertained in the teaching of communication skills could be that the inclusion of the communication content in science subjects is at the discretion of scientists in charge and therefore reflects their focus on traditional research and conventional communication with other scientists [7].

Another explanation could be that science academics already have a heavy workload within the framework of the current tertiary education system. A specific barrier that professors face in teaching communication skills is that they are specialized in a specific scientific field and cannot be expected to be responsible also for the education of undergraduate students in communication [5]. Science academics rarely have time, resources or formal education to communicate their own research to non-scientific audiences [15]; this gets even harder when it comes to developing the skills, resources and subjects required to teach such communication extensively. For this reason, it is necessary to admit that a fundamental "identifiable framework" is required to develop curricula on communication skills development [14].

Regarding Greece, it can be said that Greece has always been a place of delayed implementation of the new pedagogical principles. In Greece, the establishment of university departments aiming at communication and the evolution of communication studies only took place in 1990s [6]. As Petrou [17] claims it wouldn't be an exaggeration to say that universities "are in times of research, making an effort to deal with problems created because of massiveness and often inconsistency between the studies offered and the needs of society", a phenomenon more intensely present in Greece.

\section{CONCLUSIONS}

A general conclusion of this research is that there is no comprehensive programme of systematic and responsible university teaching of "Communication Pedagogy" at undergraduate level, which would allow students, future pedagogues, to be equipped with scientific communication knowledge, understand the technical-strategic principles for the improvement of the communication skills of both themselves and their students and keep abreast of the latest pedagogical learning theories.

This study may either be a source of inspiration to deal with the Communication Literacy in the field of education or offer aspects for further elaboration and contribute to the creation of innovative programmes for a more efficient teaching and a more efficient resolution of various conflicts among those involved in educational reality. It is the state's duty to take care of the "communication preparation" of teachers, assisting them in their difficult pedagogical and teaching work. The field of research shall be able to convince university departments to create Specialization Sectors related to the teaching of efficient communication as a method of teaching and as a method of conflict resolution. 


\section{ACKNOWLEDGMENTS}

The author would like to thank her post-doc research supervisor Dr. Panagiotis J. Stamatis, Associate Professor in University of the Aegean (Department of Sciences of Preschool Education and Educational Design) for his guidance and advice.

\section{REFERENCES}

[1] Andrade, D. The Importance of Communication in Education. https://www.techlearning.com/tl-advisor-blog/8716. 09 January, 2015

[2] Barida, M., \& Muarifah, A. The Role of Teachers' Communication Skills on Children' Well-Being in School. The 2nd International Conference on Child-Friendly Education (ICCE). Muhammadiyah Surakarta University, 2018.

[3] Bee, S. B. The Impact of Teachers' Communication Skills on Teaching: Reflections of Pre-service Teachers on their Communication Strengths and Weaknesses. Humanising Language Teaching, 2012; 14(1): 1-18.

[4] Binkley, M., Erstad, O., Herman, J., Raizen, S., Ripley, M. \& Rumble, M. Draft white paper 1: Defining 21st century skills. http://www.ericlondaits.com.ar/oei_ibertic/sites/default/files/bibliotec a/24_defining-21st-century-skills.pdf. January 2010 .

[5] Brownell, S. E., Price, J. V., \& Steinman, L. Science communication to the general public: why we need to teach undergraduate and graduate students this skill as part of their formal scientific training. Journal of Undergraduate Neuroscience Education, 2013; 12(1), E6E10.

[6] Curran, J., \& Gurevitch, M. (Eds.). Mass communication and society. Pataki, Athens, Greece, 2007.

[7] Dietz, T. Bringing values and deliberation to science communication. Proceedings of the National Academy of Sciences, 2013; 110 (Supplement 3): 14081-14087.

[8] Duta, N., Panisoara, G., \& Panisoara, I. O. The Effective Communication in Teaching. Diagnostic study regarding the academic learning motivation to students. Procedia-Social and Behavioral Sciences, 2015; 186, 1007-1012.

[9] Ghasemi, H., \& Rasekh, N. Identifying Dimensions of Communication Literacy: Thematic Analysis Approach. Journal of Health Literacy, 2020; 4(4): 18-29.

[10] GPE (Global Partnership for Education). 21st-Century Skills: What potential role for the Global Partnership for Education? A Landscape Review. https://www.globalpartnership.org/content/21st-centuryskills-what-potential-role-global-partnership-education. 13 january, 2020.

[11] Khan, A., Khan, S., Zia-Ul-Islam, S., \& Khan, M. Communication Skills of a Teacher and Its Role in the Development of the Students' Academic Success. Journal of Education and Practice, 2017; 8(1), 1821.

[12] Konstantinou, C. The School we are experiencing and the School we are claiming. Proceedings of the 2nd Panhellenic Conference "Education in the 21st century: theory and practice. In search of the attractive and efficient school. Volume A. School Life and Education Museum of EKEDISY' Hellenic Education Society ${ }^{*}$ International Board on Books for Young People - IBBY Circle of the Greek Children's Book' Greek-French school Jeanne d' Arc, Athens, Greece, 2017,37.

[13] McCroskey, J. C, Richmond, V. P., \& McCroskey, L. L. An introduction to communication in the classroom. The role of communication in teaching and training. Pearson Education, Boston, MA, United States, 2006.

[14] Mercer-Mapstone, L., \& Kuchel, L. Core skills for effective science communication: A teaching resource for undergraduate science education. International Journal of Science Education, Part B, 2017; 7(2): 181-201

[15] Metcalfe, J., \& Gascoigne, T. Science journalism in Australia. Public Understanding of Science, 1995; 4(4): 411-428.

[16] Morreale, S. P., Valenzano, J. M., \& Bauer, J. A. Why communication education is important: A third study on the centrality of the discipline's content and pedagogy. Communication Education, 2017; 66(4): 402-422.

[17] Petrou, I. Sociology. Babounakis Editions, Thessaloniki, Greece, 2016.

[18] Sharifirad, G. R., Rezaeian, M., Jazini, A., \& Etemadi, Z. S. Knowledge, attitude and performance of academic members regarding effective communication skills in education. Journal of Education and Health Promotion. 2012; 1:42

[19] Simonds, C. J., \& Cooper, P. J. Communication for the classroom teacher. Allyn \& Bacon, Boston, MA, United States, 2011.

[20] Stamatis, P. J. Preschool and Early Primary School Pedagogy. Communicative dimensions of educational process. Diadrassi Publications, Athens, Greece, 2015.

[21] Stamatis, P. J., \& Hatzinikolaou, A. M. Practices of Greek school principals for improving school climate as communication strategy. European Journal of Human Resource Management Studies, 2020; 4(2): 93-107.

[22] Zerraf, S., Zain, S., Khyati, A., Tridane, M., \& Belaaouad, S. A pedagogical approach to educational communication in the educational context. International Journal of Advanced Education and Research, 2019; 4(1): 1-14. 